(2) Open Access Full Text Article

ORIGINAL RESEARCH

\title{
Assessing Palatability of a New Amphetamine Extended-Release Tablet Formulation for the Treatment of ADHD
}

\section{Antonio Pardo \\ Thomas R King (D) \\ Eman Rafla \\ Judith C Kando}

Tris Pharma, Inc. Clinical and Medical Affairs, Monmouth Junction, NJ, USA
Antonio Pardo

Tris Pharma, Inc., 203I US Route 130,

Monmouth Junction, NJ, 08852, USA

Tel + I (732) 940-2800

Email apardo@trispharma.com
Introduction/Objective: ADHD is, for many people, a lifelong disease that requires chronic medication use. Stimulant therapy is often recommended as first-line treatment for ADHD. Adherence to stimulant treatment among patients diagnosed with ADHD is poor. Major regulatory agencies have recommended measurement of palatability for new tablet formulations. A new amphetamine extended-release tablet (AMPH ER TAB) for the treatment of attention-deficit/hyperactivity disorder (ADHD) was developed. The AMPH ER TAB has a bubblegum flavor and can be chewed or swallowed whole. In 2016, the FDA developed a draft guidance document on the topic of chewable drug tablet formulation palatability.

Methods: A palatability study of the AMPH ER TAB using the 2016 FDA guidance was conducted. Subjects were asked to assess the taste, aftertaste, and mouthfeel of the tablet formulation using a short questionnaire. Scores from the questionnaire were rated and presented.

Results: The substudy assessed 35 subjects with a mean age of $38( \pm 11)$ years. Subjects were predominantly male, non-Hispanic, and White. Most subjects rated the oral sensation/ mouth feel and taste of the tablet as positive (pleasant to very pleasant) $(70.1 \%$ and $83.6 \%$, respectively). Additionally, $86.6 \%$ of the subjects rated the strength of the taste as neutral (moderate taste) or positive (mild to no taste). Finally, $82.1 \%$ of all subjects rated the aftertaste as positive (pleasant to very pleasant) and $92.5 \%$ of subjects rated the strength of the aftertaste as neutral or positive (mild to no taste). The trends in evaluation scores for each question were similar regardless of whether the ER chewable tablet was administered under fasted or fed conditions.

Conclusion: The positive palatability data presented here will be useful for future "realworld" assessments of adherence to treatment with the AMPH ER TAB. Enhanced adherence may bolster the argument that taste, mouthfeel, and aftertaste are critical determinants of treatment adherence.

Keywords: ADHD, palatability, tablet, stimulant, amphetamine

\section{Background}

Attention-deficit/hyperactivity disorder (ADHD) is a neurobehavioral disorder characterized by pervasive impairment in symptoms of inattention, hyperactivity, and impulsivity. ${ }^{1}$ Symptoms of ADHD typically manifest in early childhood, often leading to diagnosis and treatment. Recent prevalence data indicate approximately $9.4 \%$ of children ages 2 to 17 years are diagnosed with ADHD. ${ }^{2}$ Psychopharmacologic treatment is targeted at management of symptoms of 
ADHD, and evidence exists that ADHD persists into adulthood, with a reported 40 to $66 \%$ of individuals diagnosed with ADHD as a child continuing to show symptoms of ADHD as an adult. ${ }^{3,4}$ The prevalence of adult ADHD in the United States in 2006 was $4.4 \% .{ }^{5}$ Clinical practice guidelines recommend a combination of behavior therapy and psychostimulant medication for treatment of attention-deficit/hyperactivity disorder (ADHD) in children, adolescents, and adults. ${ }^{6,7}$ Psychostimulants are often prescribed for ADHD in adults, ${ }^{8}$ and amphetamine long has been considered a mainstay of treatment for this population. ${ }^{8}$ Amphetamine is a well-established therapeutic agent for the treatment of ADHD. Since the original FDA approval of amphetamine for ADHD, various forms have been approved for use (both immediate release [IR] dosage forms, oral solutions and tablets, and extended release [ER] dosage forms, capsules, and tablets using various release technologies to enhance the pharmacokinetic profile and duration of efficacy). Adults in particular may benefit from the convenience and portability of a chewable tablet formulation of amphetamine. Tablet formuations have specific issues with regard to taste profile and palatability. Accordingly, in 2016, the US FDA issued a draft industry guidance document "Quality Attribute Considerations for Chewable Tablets" " which describes the critical quality attributes to be considered when developing chewable tablets. In addition to requesting physical characteristics assessments of the chewable tablet, it included recommendations on selection of acceptance criteria for measuring drug palatability, defined by FDA as "having a taste acceptable to the patient or has adequate masking". The original 2016 draft guidance included assessment questions asking whether the tablets were swallowed intact; does the shape and size of the chewable tablet pose a choking or bowel obstruction risk; if water is used to aid in swallowing, what volume was necessary; and with regard to tablet palatability, what was the subject's sensory experience (eg, taste, mouth feel, and aftertaste)? The guidance document was updated to final status in 2018, and the recommendations included changes to several important factors for consideration in assessing acceptability of chewable tablets, including specific data on hardness, disintegration, dissolution, and performance in simulated physiologic media. ${ }^{10}$ These data are now recommended, and some elements are required as part of New Drug Application (NDA) and Abbreviated NDA (ANDA) submissions.
Tris Pharma, Inc. has developed an extended-release amphetamine tablet formulation (AMPH ER TAB; Dyanavel ${ }^{\circledR}$ XR Extended-Release Tablet, Monmouth Junction, NJ). The AMPH ER TAB is a scalemic amphetamine formulation comprising $\mathrm{d}$ - and l-amphetamine in a 3:2.1 ratio and uses the proprietary LiquiXR ${ }^{\circledR}$ drug delivery technology, which utilizes an ion-exchange resin that complexes with amphetamine or any other active moiety that can be protonated and is water-soluble. In 2016, a pharmacokinetic (PK) study was performed to assess the relative bioavailability of AMPH ER TAB $20 \mathrm{mg}$ (swallowed whole or chewed) compared with a single dose of amphetamine ER oral suspension (Dyanavel ${ }^{\circledR} \mathrm{XR}$ Extended Release Oral Suspension, Tris Pharma, Inc., Monmouth Junction, NJ). This PK study was conducted in 36 adult subjects under fasted and fed conditions. The details and results of the PK study have been reported elsewhere. ${ }^{11}$ As part of the PK study, a substudy was performed that evaluated the palatability of the AMPH ER TAB using the original 2016 FDA Guidance. This study and the parent PK study were performed in accordance with the Declarations of Helsinki.

\section{Methods}

The parent PK study included two arms in a crossover structure that were subsequently used for the palatability analysis. One arm comprised subjects who fasted for 10 hours (as part of the primary PK study), then chewed the AMPH ER TAB and consumed water, and the second included subjects who consumed a full high-fat breakfast, then chewed the tablet, followed by water. All subjects were intended to be included in both arms. The protocol and informed consent documentation were approved by an Institutional Review Board (Salus IRB, Austin, TX).

All subjects provided informed consent for the parent PK study, and at the time of consent, they were also informed of the palatability assessment. Prior to drug administration, subjects were instructed not to touch or spit out the study drug. A single $20 \mathrm{mg}$ dose (one AMPH ER TAB) was administered according to the randomization scheme. Designated clinic staff placed the tablet into the subject's mouth and onto the subject's tongue directly from the dosing vial at the specified time and instructed the subject not to swallow the tablet whole. The subjects then chewed the tablet thoroughly in an up/ down motion for 20 seconds. The subjects then drank approximately 2 oz. ( \pm 0.1 oz.) of the 8 oz. $( \pm 0.2$ oz. $)$ room temperature potable water to assist in consuming 
any of the disintegrated tablet remaining in the subject's mouth. Clinic staff performed a check after approximately 20 seconds to confirm no residual medication was left inside the subject's mouth. The subjects were then asked to consume the remaining room temperature water by lightly "swishing" the water in their mouth and swallowing. The time of dosing was recorded as the time the tablet was placed on the subject's tongue.

\section{Palatability Questionnaire}

The questionnaire was structured as follows: 5 questions were posed asking the subjects to respond: "1. Rate the oral sensation/mouthfeel of the drug product"; " 2 . Rate the taste of the drug product"; " 3 . How strong is the taste?"; "4. Rate the aftertaste of the drug product"; and " 5 . How strong is the aftertaste?". For questions 1, 2, and 4, the range of responses was: "very unpleasant, unpleasant, no sensation/mouthfeel, pleasant, very pleasant." For questions 3 and 5, the range of responses was: "very strong, strong, moderate, mild, no taste." Subjects were given time to read the palatability questionnaire and consider its content prior to responding. They were permitted ask questions about the meaning (eg, "what is meant by ...") of the questions at any time during questionnaire administration. Subjects were required to complete the questionnaire within 10 minutes of consuming the tablet and were instructed to initial the document once completed.

Clinic staff were instructed to ensure that only one response was given per question.

\section{Analysis}

The overall palatability response scoring system is outlined in Table 1. The dataset chosen for analysis included all questions that were completed and had no more than one response per question. Responses to each question were assigned a numerical value from 1 through 5 , following a sequential order from the top of the scale to the bottom (eg, a palatability rating of "very unpleasant" or "very strong" carried a value of 1 , and "very pleasant" or "no aftertaste" was assigned a value of 5. Descriptive statistics were calculated and reported for the original questions and scores as described for palatability and for taste strength. Acceptability responses were segregated into 3 discrete categories ("negative", "neutral", or "positive") which were defined based on the original scales: measures of 1 or 2 were considered "negative", 3 was graded "neutral", and 4 and 5 were assessed as "positive". Individual scores were presented by treatment (fasted or
Table I Palatability Response Data Scoring

\begin{tabular}{|c|c|c|c|}
\hline \multicolumn{2}{|l|}{ Response } & \multirow[t]{2}{*}{ Score } & \multirow[t]{2}{*}{ Acceptability } \\
\hline $\begin{array}{l}\text { Palatability } \\
\text { (Questions I, 2, 4) }\end{array}$ & $\begin{array}{l}\text { Strength } \\
\text { (Questions } \\
3,5)\end{array}$ & & \\
\hline Very unpleasant & Very strong & I & \multirow[t]{2}{*}{ Negative } \\
\hline Unpleasant & Strong & 2 & \\
\hline $\begin{array}{l}\text { No sensation/ } \\
\text { mouthfeel (or } \\
\text { after[taste]) }\end{array}$ & Moderate & 3 & Neutral \\
\hline Pleasant & Mild & 4 & \multirow[t]{2}{*}{ Positive } \\
\hline Very pleasant & No (after) taste & 5 & \\
\hline
\end{tabular}

fed) along with descriptive statistics. Frequency tables were generated that included the number and percent of subjects responding in each category. No inferential statistical analyses were performed.

\section{Results}

\section{Demography}

The parent PK study enrolled 36 healthy adult subjects. Subjects who had completed at least one question on the palatability questionnaire were included in the palatability dataset. One subject was dismissed from the study prior to Period 2 dosing; that subject did not complete the palatability questionnaire for Fed nor Fasted AMPH ER TAB and was excluded from the palatability dataset. Two subjects discontinued from the study prior to receiving Fasted AMPH ER TAB but received Fed AMPH ER TAB, therefore 33 subjects completed the questionnaire for the Fasted arm. One subject discontinued from the study prior to receiving Fed AMPH ER TAB but received Fasted AMPH ER TAB, therefore 34 subjects completed the questionnaire in the Fed AMPH ER TAB arm.

The palatability subset yielded 35 subjects with a mean age of $38( \pm 11)$ years, with most subjects falling into the 18 to 40 -year-old group. The population had a mean height of $171.8( \pm 9.0) \mathrm{cm}$, a mean weight of $78.6 \mathrm{Kg}$, and was mostly Male, non-Hispanic, and White. Complete demographic characteristics are outlined in Table 2.

\section{Analysis Results}

The overall frequency distributions by Fed/Fasted arms is listed in Table 3 and presented graphically in Figure 1A-E. The results of the categorized palatability analysis 
Table 2 Palatability Analysis Group

\begin{tabular}{|c|c|c|}
\hline $\begin{array}{l}\text { Demographic } \\
\text { Characteristic }\end{array}$ & Statistics & $\begin{array}{l}\text { Palatability } \\
\text { Dataset } N=35\end{array}$ \\
\hline Age (years) & $\begin{array}{l}\text { Mean } \pm \text { SD } \\
\text { Median } \\
\text { Range }\end{array}$ & $\begin{array}{l}38 \pm 11 \\
37 \\
19-55\end{array}$ \\
\hline Height (cm) & $\begin{array}{l}\text { Mean } \pm \text { SD } \\
\text { Median } \\
\text { Range }\end{array}$ & $\begin{array}{l}171.8 \pm 9.0 \\
172.9 \\
155.9-188.6\end{array}$ \\
\hline Weight (kg) & $\begin{array}{l}\text { Mean } \pm S D \\
\text { Median } \\
\text { Range }\end{array}$ & $\begin{array}{l}78.6 \pm 13.8 \\
75.6 \\
51.2-108.4\end{array}$ \\
\hline BMI $\left(\mathrm{kg} / \mathrm{m}^{2}\right)$ & $\begin{array}{l}\text { Mean } \pm \text { SD } \\
\text { Median } \\
\text { Range }\end{array}$ & $\begin{array}{l}26.5 \pm 3.3 \\
27.4 \\
|9.0-3| . \mid\end{array}$ \\
\hline Gender (n, \%) & $\begin{array}{l}\text { Female } \\
\text { Male }\end{array}$ & $\begin{array}{l}16(45.7 \%) \\
19(54.3 \%)\end{array}$ \\
\hline Ethnicity (n, \%) & $\begin{array}{l}\text { Hispanic or Latino } \\
\text { Not Hispanic or } \\
\text { Latino }\end{array}$ & $\begin{array}{l}\text { I }(2.9 \%) \\
34(97.1 \%)\end{array}$ \\
\hline Race (n, \%) & $\begin{array}{l}\text { Black or African } \\
\text { American } \\
\text { Multi-Racial } \\
\text { White }\end{array}$ & $\begin{array}{l}26(74.3 \%) \\
3(8.6 \%) \\
6(17.1 \%)\end{array}$ \\
\hline
\end{tabular}

indicated that the majority of subjects rated the oral sensation/mouth feel of the AMPH ER TAB (after fasting and when fed) (Question 1) and the taste of the AMPH ER TAB (Question 2) as positive (pleasant to very pleasant) (70.1\% and $83.6 \%$, respectively).

When evaluating the strength of the drug taste (Question 3), 86.6\% of subjects rated the strength as positive (mild to no taste) or neutral (moderate taste). Regarding the aftertaste, $82.1 \%$ of all subjects rated the aftertaste of the AMPH ER TAB (Question 4) as positive (pleasant to very pleasant) and $92.5 \%$ of subjects rated the strength of the aftertaste as neutral or positive (mild to no taste). The trends in evaluation scores for each question were similar regardless of whether the ER chewable tablet was administered under fasted conditions or after a meal.

\section{Discussion}

One half of ADHD patients do not adhere to treatment guidelines $^{12}$ or worse, discontinue pharmacologic treatment within 2-3 years of starting. ${ }^{13,14}$ Literature reviews of reasons for discontinuation of medication regimens include tolerability, stigma, perceived lack of efficacy, and poor adherence as major contributing factors for noncompliance. ${ }^{15}$ The palatability of a drug is a known contributing factor in ensuring patient

Table 3 Frequency Distribution of Evaluation Score (Categorized Data) by Treatment

\begin{tabular}{|c|c|c|c|c|c|}
\hline \multirow[b]{2}{*}{ Question } & \multirow[b]{2}{*}{ Treatment } & \multirow[b]{2}{*}{$\mathbf{N}$} & \multicolumn{3}{|c|}{ Evaluation Score (\%) } \\
\hline & & & I = Negative & $2=$ Neutral & $3=$ Positive \\
\hline \multirow[t]{2}{*}{ I. Rate the oral sensation/mouth feel of the drug product } & Fasted & 33 & 7 (2I.2\%) & 5 (15.2\%) & $21(63.6 \%)$ \\
\hline & Fed & 34 & $3(8.8 \%)$ & 5 (14.7\%) & $26(76.5 \%)$ \\
\hline \multirow{3}{*}{ 2. Rate the taste of the drug product } & & Overall & $14.9 \%$ & $14.9 \%$ & $70.1 \%$ \\
\hline & Fasted & 33 & 5 (I5.2\%) & I (3.0\%) & 27 (8I.8\%) \\
\hline & Fed & 34 & $4(11.8 \%)$ & I (2.9\%) & 29 (85.3\%) \\
\hline \multirow{3}{*}{ 3. How strong is the taste? } & & Overall & $13.4 \%$ & $3.0 \%$ & $83.6 \%$ \\
\hline & Fasted & 33 & 5 (I5.2\%) & 15 (45.5\%) & $13(39.4 \%)$ \\
\hline & Fed & 34 & $4(11.8 \%)$ & $14(41.2 \%)$ & $16(47.1 \%)$ \\
\hline \multirow{3}{*}{ 4. Rate the aftertaste of the drug product } & & Overall & $13.4 \%$ & $43.3 \%$ & $43.3 \%$ \\
\hline & Fasted & 33 & $2(6.1 \%)$ & $4(12.1 \%)$ & 27 (81.8\%) \\
\hline & Fed & 34 & $0(0.0 \%)$ & $6(17.6 \%)$ & $28(82.4 \%)$ \\
\hline \multirow{4}{*}{ 5. How strong is the aftertaste? } & & Overall & $3.0 \%$ & $14.9 \%$ & $82.1 \%$ \\
\hline & Fasted & 33 & $2(6.1 \%)$ & 17 (5I.5\%) & $14(42.4 \%)$ \\
\hline & Fed & 34 & $3(8.8 \%)$ & $10(29.4 \%)$ & $21(61.8 \%)$ \\
\hline & & Overall & $7.5 \%$ & $40.3 \%$ & $52.2 \%$ \\
\hline
\end{tabular}

Notes: Fasted= subject fasted for 10 hours, then consumed a chewed $20 \mathrm{mg}$ AMPH ER TAB. Fed= subject was fed a high-fat, high-calorie breakfast, then consumed a chewed $20 \mathrm{mg}$ AMPH ER TAB. 
A

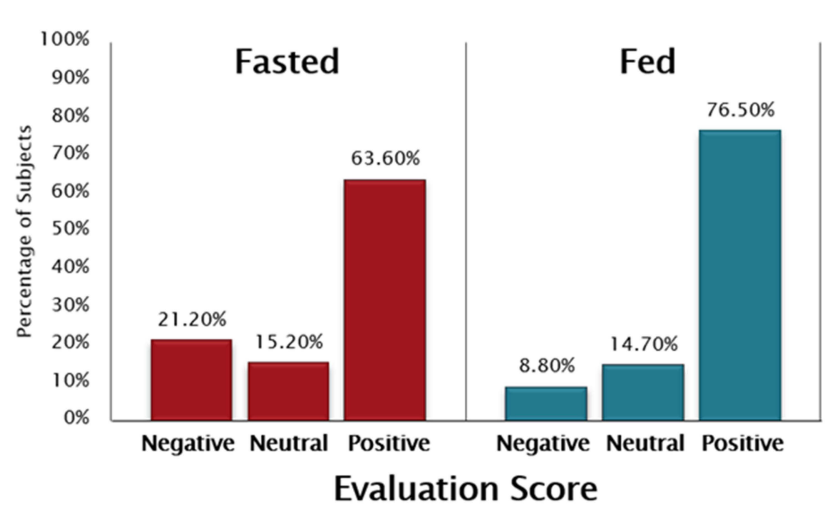

C

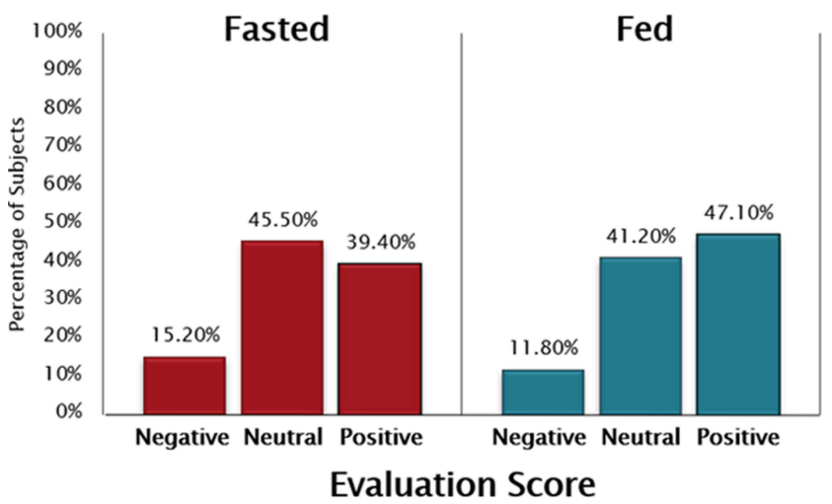

B

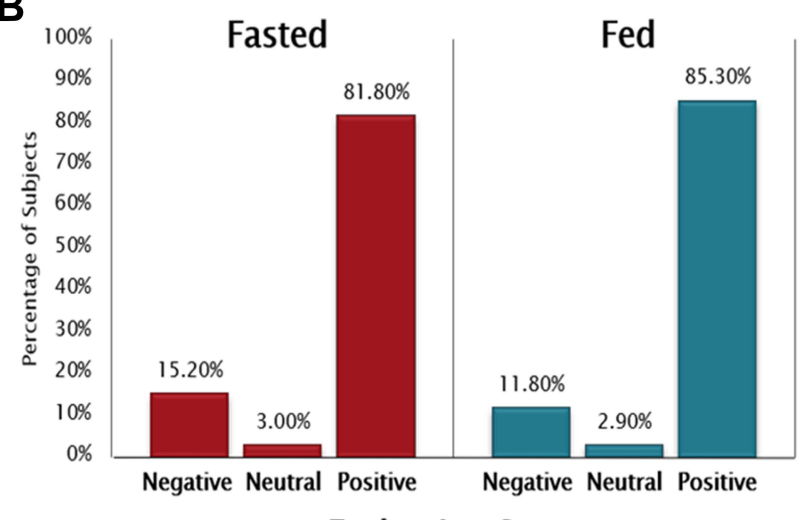

D

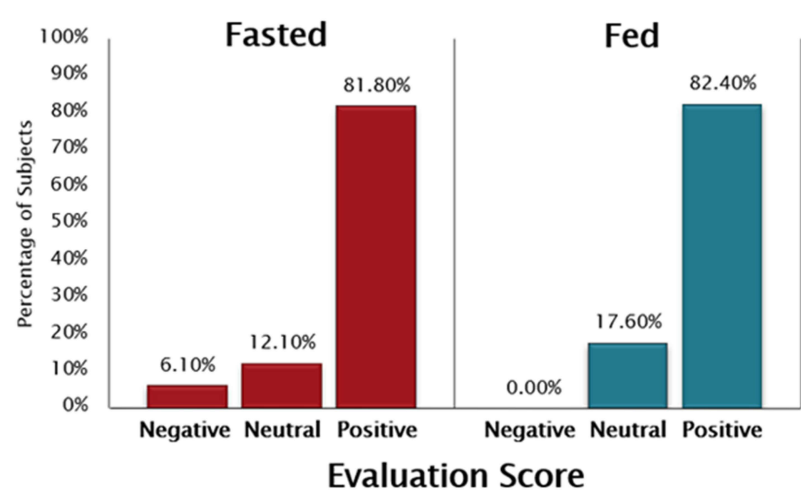

E

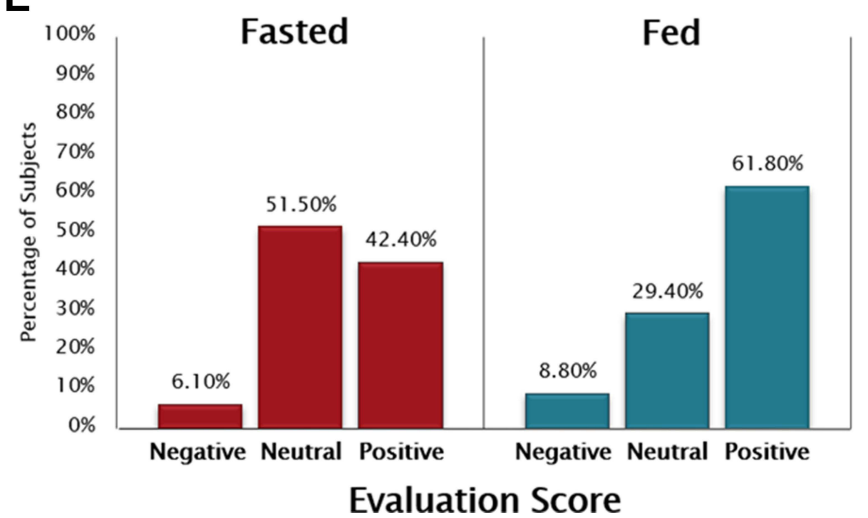

Figure I (A) Rate the oral sensation/mouth feel of the drug product: (B) Rate the taste of the drug product. (C) How strong is the taste? (D) Rate the aftertaste of the drug product. (E) How strong is the aftertaste?

Note: Treatment $A=$ fasted subjects (red columns). Treatment $B=$ fed subjects (blue columns). Negative $=$ very unpleasant or unpleasant. Neutral $=$ no sensation. Positive $=$ pleasant or very pleasant.

acceptability of a drug regimen, and thusly positively impacts patient adherence. ${ }^{16}$ The importance of palatability as an adherence factor is recognized by the US FDA, ${ }^{10}$ the EU National Institute for Health and Care Excellence ${ }^{17}$ and European Medicines Agency. ${ }^{18}$ Several studies measuring the impact of palatability on drug preferability and adherence have been performed for therapeutics as diverse as soft gel capsules, ${ }^{19}$ chewable tablets, ${ }^{20}$ various formulations for antibiotics, ${ }^{21}$ antivirals, ${ }^{22}$ and other drug treatment formulations. Additionally, instruments have been developed to assess patient and/or caregiver acceptability of drug regimens. ${ }^{23}$ Palatability as an adherence factor has traditionally focused on pediatric patients, generally in antibiotic development, but research has demonstrated that many of the same acceptability factors that apply to treatments for children also apply to adult patients. $^{16}$ 
As part of the development of the AMPH ER TAB, the palatability was assessed using a protocol that placed emphasis on several acceptance factors considered important to FDA. The substudy assessed overall palatability based on the subject's sensory experience criteria when consuming the tablet: its mouthfeel, taste, and aftertaste. In this assessment, most subjects rated the overall sensory experience as pleasant or very pleasant, regardless of whether the subject had fasted or had consumed a full breakfast prior to administration of the medication.

This study design has some important limitations: it measured palatability in a healthy subject population under rigorous, controlled circumstances. Whether or not this influenced the subject's feedback is arguable. The study enrolled a relatively small number of healthy adult patients; therefore, the results of this study are not necessarily generalizable to the pediatric population; perhaps additional studies can be undertaken with children. As indicated earlier, the palatability assessment protocol employed in this study was based on details included in the original 2016 FDA guidance, as this study was performed before the newer version was released in 2018. In the subsequent approved version, the queries were rewritten to reflect a more holistic yet detailed approach to assessment of palatability: was the subject's sensory experience associated with chewing the tablet acceptable (eg, taste, mouthfeel, and aftertaste); did subjects have difficulty in thoroughly chewing the tablet (ie, were the tablets inadvertently swallowed intact); if inadvertently swallowed intact, does the shape and size of the chewable tablet pose a choking or bowel obstruction risk; and if water was used to aid swallowing, what was the volume? This study focused on the palatability aspect of the tablet formulation, but these other factors clearly impact acceptability and therefore adherence to a regimen.

The positive palatability data presented here will be useful for future "real-world" assessments of adherence to treatment with the AMPH ER TAB. Enhanced adherence may bolster the argument that taste, mouthfeel, and aftertaste are more than desirable attributes in a tablet- it may mean that they are critical determinants of treatment adherence.

\section{Acknowledgments and Disclosures}

The Authors would like to thank Payal Naik, MPH, for her assistance in the preparation of this manuscript. The research upon which this manuscript is based was funded by Tris Pharma, Inc., the manufacturer and marketer of the product. This work is not under consideration for publication elsewhere.
The work is original. The abstract of this paper was presented at the 2020 American Academy of Child and Adolescent Psychiatry as a poster presentation with interim findings. The poster's abstract was published in The Journal of the American Academy of Child \& Adolescent Psychiatry: The Scientific Proceedings of the 67th Annual Meeting of the American Academy of Child \& Adolescent Psychiatry VOLUME 59, ISSUE 10, SUPPLEMENT, I, OCTOBER 01, 2020 DOI: https://doi.org/10.1016/S0890-8567(20)31848-7.

\section{Disclosure}

AP, ER, and JCK are compensated employees of Tris Pharma, Inc., the developer and manufacturer of the product that is the subject of this work. JCK owns stock from Johnson and Johnson and Takeda. TRK was an employee of Tris Pharma, Inc. at the time the study was conducted. The authors report no other conflicts of interest in this work.

\section{References}

1. American Psychiatric Association. Diagnostic and Statistical Manual of Mental Disorders (DSM-5). APA Publications; May 222013.

2. Danielson ML, Bitsko RH, Ghandour RM, Holbrook JR, Kogan MD, Blumberg SJ. Prevalence of parent-reported ADHD diagnosis and associated treatment among U.S. children and adolescents. $J$ Clin Child Adolesc Psychiatry. 2018;47(2):199-212. doi:10.1080/ 15374416.2017.1417860

3. Barkley RA, Fischer M, Smallish L, Fletcher K. The persistence of attention-deficit/hyperactivity disorder into young adulthood as a function of reporting source and definition of disorder. $J$ Abnorm Psychol. 2002;111(2):279-289. doi:10.1037/0021-843X.111.2.279

4. Lara C, Fayyad J, DeGraaf R, et al. Childhood predictors of adult attention-deficit/ hyperactivity disorder: results from the World Health Organization World mental health survey initiative. Biol Psychiatry. 2009;65(1):46-54. doi:10.1016/j.biopsych.2008.10.005

5. Kessler RC, Adler L, Barkley R, et al. The prevalence and correlates of adult ADHD in the united states: results from the national comorbidity survey replication. Am $J$ Psychiatry. 2006;163(4):716-723. doi:10.1176/ajp.2006.163.4.716

6. Wolraich M, Brown L, Brown RT, et al. Subcommittee on attention-deficit/hyperactivity disorder; steering committee on quality improvement and management. ADHD: clinical practice guideline for the diagnosis, evaluation, and treatment of attention deficit/hyperactivity disorder in children and adolescents. Pediatrics. 2011;128(5):1007 1022. doi:10.1542/peds.2011-2654

7. Pliszka S; AACAP Working Group on Quality Issues. AACAP work group on quality issues practice parameter for the assessment and treatment of children and adolescents with attention-deficit/hyperactivity disorder. J Am Acad Child Adolesc Psychiatry. 2007;46 (7):894-921. doi:10.1097/chi.0b013e318054e724

8. McGough JJ. Treatment controversies in adult ADHD. Am J Psychiatry. 2016;173(10):960-966. doi:10.1176/appi. ajp.2016.15091207

9. US Department of Health and Human Services, FDA. Quality attribute considerations for chewable tablets, guidance for industry; June 2016. Available from: http://www.fda.gov/Drugs/ GuidanceComplianceRegulatoryInformation/Guidances/default.htm. Accessed November 17, 2020. 
10. US Department of Health and Human Services, FDA. Quality attribute considerations for chewable tablets, guidance for industry; August 2018. Available from: http://www.fda.gov/Drugs/ GuidanceComplianceRegulatoryInformation/Guidances/default.htm. Accessed November 17, 2020.

11. Pardo A, Kando JC, Rafla E, Herman BK. Single dose pharmacokinetics of amphetamine extended-release tablets compared with amphetamine extended-release oral suspension. CNS Spectr. 2020;25(6):774-781. doi:10.1017/S1092852919001676.

12. Ferrin M, Ruiz-Veguilla M, Blanc-Betes M, et al. Evaluation of attitudes towards treatment in adolescents with attention deficit hyperactivity disorder (ADHD). Eur Child Adolesc Psychiatry. 2012;21(7):387-401. doi:10.1007/s00787-012-0277-6

13. Zetterqvist J, Asherson P, Halldner L, Långström N, Larsson H. Stimulant and non-stimulant attention deficit/hyperactivity disorder drug use: total population study of trends and discontinuation patterns 2006-2009. Acta Psychiatr Scand. 2013;128(1):70-77. doi:10.1111/ acps. 12004.

14. Garbe E, Mikolajczyk RT, Banaschewski T, et al. Drug treatment patterns of attention-deficit/hyperactivity disorder in children and adolescents in Germany: results from a large population-based cohort study. J Child Adolesc Psychopharmacol. 2012;22(6):452-458. doi:10.1089/cap.2012.0022

15. Garjia K, Lu M, Sikirica V, et al. Adherence, persistence, and medication discontinuation in patients with attention-deficit/hyperactivity disorder $\neg \mathrm{a}$ systematic literature review. Neuro Dis Treat. 2014;10:1543-1569.

16. Shariff ZB, Dahmash DT, Kirby DJ, Missaghi S, Rajabi-Siahboomi A, Maidment ID. Does the formulation of oral solid dosage forms affect acceptance and adherence in older patients? A mixed methods systematic Review. J Am Med Dir Assoc. 2020;21(8):1015-1023.e8. doi:10.1016/j.jamda.2020.01.108.
17. National Institute for Health and Care Excellence. Medicines optimization: the safe and effective use of medicines to enable the best possible outcomes; 2015. Available from: https://www.nice.org.uk/ guidance/ng5/chapter/introduction. Accessed November 15, 2020.

18. European Medicines Agency. Guidelines on pharmaceutical development of medicines for paediatric use; August 1, 2013. Available from: http://www.ema.europa.eu/docs/en_GB/document_library/ Scientific_guideline/2013/07/WC500147002.pdf. Accessed November 12, 2020.

19. Jones WJ 3rd, Francis JJ. Softgels: consumer perceptions and market impact relative to other oral dosage forms. Adv Ther. 2000;17 (5):213-221. doi:10.1007/BF02853160

20. Rees TP, Howe I. A Randomised, single-blind, crossover comparison of the acceptability of the calcium and vitamin $\mathrm{D}_{3}$ supplements calcichew $\mathrm{D}_{3}$ Forte $^{\circledR}$ and Ad Cal D ${ }^{\circledR}$ in elderly patients. Curr Med Res Opin. 2001;16(4):245-251. doi:10.1185/030079901750120178

21. Baguley D, Lim E, Bevan A, Pallet A, Faust SN. Prescribing for children - taste and palatability affect adherence to antibiotics: a review. Arch Dis Child. 2012;97(3):293-297. doi:10.1136/archdischild-2011-300909.

22. Phillips SC, Rolan PE, Posner J, et al. Greater ease of swallowing of a new film-coated $800-\mathrm{mg}$ dispersible acyclovir tablet compared to the standard $800-\mathrm{mg}$ tablet in elderly volunteers. J Pharm Med. 1992;2:259-262.

23. Turner-Bowker DM, An Haack K, Krohe M, et al. Development and content validation of the Pediatric Oral Medicines Acceptability Questionnaires (P-OMAQ): patient-reported and caregiver-reported outcome measures. J Patient Rep Outcomes. 2020;4(1):80. doi:10.1186/s41687-020-00246-1
Drug Design, Development and Therapy

\section{Publish your work in this journal}

Drug Design, Development and Therapy is an international, peerreviewed open-access journal that spans the spectrum of drug design and development through to clinical applications. Clinical outcomes, patient safety, and programs for the development and effective, safe, and sustained use of medicines are a feature of the journal, which has also

\section{Dovepress}

been accepted for indexing on PubMed Central. The manuscript management system is completely online and includes a very quick and fair peer-review system, which is all easy to use. Visit http://www. dovepress.com/testimonials.php to read real quotes from published authors. 